\title{
Seventy Nine
}

National Cancer Institute

\section{Source}

National Cancer Institute. Seventy Nine. NCI Thesaurus. Code C105791.

A natural number greater than seventy-eight and less than eighty and the quantity that it denotes. 